\title{
Chemotherapy: oral side effects and dental interventions. A review of the literature
}

\author{
Athanasios Poulopoulos, Petros Papadopoulos, Dimitrios Andreadis \\ Department of Oral Medicine and Oral Pathology, Dental School, Aristotle University of Thessaloniki, 54124 Thessaloniki, Greece.
}

Correspondence to: Dr. Dimitrios Andreadis, Department of Oral Medicine and Oral Pathology, School of Dentistry, Aristotle University of Thessaloniki, 54124 Thessaloniki, Greece. E-mail: dandrea@dent.auth.gr

How to cite this article: Poulopoulos A, Papadopoulos P, Andreadis D. Chemotherapy: oral side effects and dental interventions. A review of the literature. Stomatological Dis Sci 2017;1:35-49.

Dr. Dimitrios Andreadis is an Assistant Professor of Oral Medicine/Pathology, School of Dentistry, Aristotle
University of Thessaloniki, Greece. His current clinical/research interests include Diagnosis (Clinical and
Microscopic) of Oral Diseases, HPV in Oral Diseases, Oral Cancer, Mucocutaneous Diseases, and Salivary/Oral
Stem Cell Biology in co-operation with Laboratory of Molecular Biology, Department of Conservative Dentistry,
Periodontology/Preventive Dentistry, Medical University of Hannover, Germany. He is a member of European
Association of Oral Medicine, International Association of Oral Pathology and International Association for Dental
Research. He participated in more than 50 published manuscripts, more than 100 presentations and serves as
invited reviewer in more than 15 journals.

Article history:

Received: 05-03-2017

Accepted: 29-03-2017

Published: 29-06-2017

Key words:

Chemotherapy,

oral side effects,

oral mucositis,

oral infections

\begin{abstract}
Even with the evolution of chemotherapeutic procedures and agents, chemotherapy may cause certain side effects that impair the patients' quality of life. The aim of this review is to isolate and describe the oral side effects arising only from chemotherapy and focus on the dentist's contribution to their management. This paper comprises an extensive literature review of the main side effects affecting the oral health status of patients' undergoing chemotherapy procedures. In addition, it describes the dentist's contribution in the treatment of such patients before, throughout and after antineoplastic therapy. In conclusion, the oral cavity is a usual site of discomfort and pain caused by chemotherapy, making the dentist's contribution to the patient's relief imperative.
\end{abstract}

\section{INTRODUCTION}

The first attempt to utilize chemotherapy in oncology was in 1942 using mustard nitrogen against malignant lymphoma. ${ }^{[1]}$ Since then many efforts have taken place toward the improvement of chemotherapy agents, the analysis of their action, and the combination of their use. Currently, the anticancer drugs are either cytostatic or cytotoxic. Cytostatic drugs focus on the blocking of tumor cell proliferation, while the cytotoxic drugs focus on the destruction of the cells. ${ }^{[2]}$ However, the evolution of the chemotherapeutic procedures and agents may cause side effects that impair the patients' life as well as the treatment of collateral issues. The

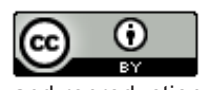
identical terms

For reprints contact: service@oaepublish.com

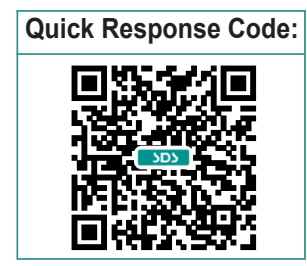


aim of this review is to isolate and describe the oral side effects rising from chemotherapy and focus on the dentist's role in the oral management of these patients.

This paper comprises an extensive literature review of the main side effects affecting the oral health status of patients' undergoing chemotherapy procedures. In addition, it describes the dentist's contribution in the treatment of such patients before, throughout, and after antineoplastic therapy. A PubMed-MEDLINE search was completed using the following keywords and phrases: chemotherapy, side effects, oral complications, oral mucositis, peripheral neuropathy, osteonecrosis of the jaw, dental management of a chemotherapy patient, teeth abnormalities caused by chemotherapy, prevention of oral mucositis, and cutaneous adverse reactions. The study focused on the papers published in the last 25 years. In total, 94 publications were taken into consideration.

\section{TOXICITY OF CHEMOTHERAPY}

The extent of toxicity upon normal tissues seems to be correlated to the dose of the antineoplastic drug used, and it is also related to the frequency of the agent's administration. Many drugs target rapidly proliferating cells; however, they have the same action upon rapidly proliferating normal tissues such as bone marrow, intestinal mucosa, oral mucosa, hair follicles, and gonads. Particularly in the oral mucosa, they destroy the basal cells of the mucosal layer, and their replacement or turnover is affected resulting in mucosal ulceration. ${ }^{[3]}$ There are also indirect toxic effects caused by procedures that take place far from the oral cavity but have a negative impact upon it, such as myelosuppression or immune cells destruction. Moreover, salivary enzymes' function is impaired. ${ }^{[4,5]}$ It's of great importance to underline the fact that many anticancer drugs cause damage to the DNA of cells, resulting in mutations and chromosomal abnormalities. They seem to act as carcinogens especially after long term treatments. Patients that undergo continuous chemotherapy are at a greater risk of presenting with a secondary malignancy, such as acute leukemia, arising two to six years after the beginning of the treatment. ${ }^{[6]}$

Disorders in the activity of certain enzymes that participate in the metabolism of antineoplastic drugs can be determined by genetic factors or by other medication. These disorders may have a particular effect on toxicity. As mentioned above, damage caused by chemotherapy follows an attack on the DNA of cells. Thus patients that present with inadequate DNA repair are prone to complications caused by anticancer drugs. ${ }^{[7]}$

\section{GENERAL SIDE EFFECTS OF CHEMOTHERAPY}

There are more than 100 different chemotherapy drugs which cause different general side effects such as bone marrow suppression, ${ }^{[8]}$ (leucopenia appears the 10th day of the chemotherapeutic course while thrombocytopenia after 10-14 days), ${ }^{[9]}$ anemia (not a common adverse effect of chemotherapy), and hair loss (common manifestation of chemotherapy). ${ }^{[2]}$ Other side effects aredefects in spermatogenesis (frequently observed in chemotherapy), ${ }^{[10]}$ nausea and vomiting (two of the most frequent side effects of chemotherapy), ${ }^{[11]}$ fatigue (common symptom present during chemotherapy), diarrhea, ${ }^{[1]}$ handfoot syndrome (Palmar-plantar erythrodysesthesia, acral erythema or Burgdorf reaction), ${ }^{[12]}$ cardiotoxicity (commonly observed after chemotherapy) (associated with both older and newer therapies which may lead to left ventricular impairment or congestive heart failure, or they can cause hypertension. Additionally, thromboembolism, pericardial thickening or cardiac arrhythmias), ${ }^{[13]}$ reactivation of hepatitis $B,{ }^{[14]}$ neurologic complications (neurotoxicity after chemotherapy includes seizures, peripheral and cranial neuropathy, myelopathy, aseptic meningitis, cerebellar syndrome, stroke, and encephalitis). ${ }^{[15-17]}$ Notably chemotherapyinduced peripheral neuropathy (CIPN) is possible to engage oral cavity and other sites simultaneously. There are several types of drugs that cause CIPN. These drugs are DNA alkylating agents (platinum derivatives such as cisplatin, carboplatin, and oxaliplatin), microtubule-targeting (taxanes such as docetaxel and paclitaxel, epothilones such as ixabepilone, vinca alkaloids such as vincristine and podophyllin analogs) and other drugs such as proteasome inhibitors. Neurotoxicity can appear in up to $97 \%$ of patients treated with oxaliplatin, ${ }^{[18]}$ whichis manifested in an acute or chronic form. The acute form is characterized by hyper-excitability; whereas, paresthesias in the mouth and throat are common symptoms. The chronic form is characterized by sensory paresthesias, dysesthesias, and ataxia of the extremities. Furthermore, endocrine disorders (hypothyroidism), ${ }^{[19]}$ liver disease, and cutaneous disordersclosely related to targeted chemotherapy (rash, xerosis, paronychia) ${ }^{[20]}$ have been related to chemotherapy.

\section{ORAL SIDE EFFECTS}

\section{Oral mucositis}

Among the most common adverse effects of chemotherapy is oral mucositis (OM). It is a painful inflammatory reaction of the oral mucosa. OM is 
characterized by infiltration of the inflammatory cells followed by epithelial disruption and ulceration. It arises 4-7 days after the initiation of a high dose course and disappears 2-4 weeks after the treatment is completed. Drugs that commonly cause $\mathrm{OM}$ are doxorubicin, bleomycin, fluorouracil, or methotrexate. ${ }^{[21]}$

Risk factors associated with $\mathrm{OM}$ are related to the therapy as well as the patients' characteristics. Studies have indicated that the higher the dose and frequency of the drug, the higher the risk of developing OM. The type of the agent affects the probability of OM. Drugs that affect DNA syntheses such as antimetabolites (methotrexate, 5-Fluorouracil) and purine analogs, increase the incidence of OM up to $60 \%$. The fact that drugs such as methotrexate and etoposide are secreted in saliva favors oral toxicity. ${ }^{[22]}$ Risk factors related to patients' characteristics are age, malnutrition, preexisting medical problems, poor oral health, trauma, liver disease, and kidney functional status. Periodontal disease increases the risk of OM. Pathogens such as Porfyromonas gingivalis, as well as fungi and viruses, seem to be responsible for ulceration and mucositis. ${ }^{[23]}$ Genes that determine the availability of active drug metabolites are related to the risk of development of mucositis. For example, the polymorphism associated with the expression of tumor necrosis factor alpha $(\mathrm{TNF}-\alpha)$ has been implicated in OM. ${ }^{[24]}$

Pathogenesis of OM is mainly described by a "stage model". During the initiation phase, the DNA strand breaks causing trauma on the basal epithelial, submucosal, and endothelial cells. Thus, epithelial proliferation in impaired. Injured tissue releases reactive oxygen species (ROS) which damage DNA. Throughout the damage phase, submucosal cells express genes, such as c-jun, c-fos, and Erg-1, which lead to activation of certain transduction pathways. ROS can damage cell membranes, stimulate macrophages, and cause activation of transcription factors. Among these factors, the most important is nuclear factor kappa $\mathrm{B}(\mathrm{NF}-\kappa \mathrm{B})$. NF- $\mathrm{kB}$ is considered to participate in pathways responsible for inflammation in mucositis. NF$\kappa B$, together with cytokines such as TNF- $\alpha$, interleukin (IL)-6, IL-1b, ceramide and matrix metalloproteinases reach their highest level during chemotherapy. Many of these molecules are capable of changing the local tissue response through feedback loops. Mucosal damage causes the release of these factors, leading to the positive feedback loop that exaggerates the mucosal destruction. At the ulcerative phase, mucosal integrity is lost, accompanied by bacterial colonization and a massive leukocytic infiltrate. The products of the bacterial cell wall stimulate macrophages, which in turn produce cytokines. At the final healing stage, keratinocytes, stimulated by extracellular matrix, migrate and proliferate to reconstruct epithelial layers. ${ }^{[23]}$ The hematopoiesis resolves, the inflammation resolves, and the stromal fibroblasts are remodeled. ${ }^{[25]}$

Mucositis is at its peak at 7-10 days after chemotherapy. Its first sign is erythema, followed by a burning sensation. Edema and ulceration are present and affect basic functions such as speech, swallowing, and eating. ${ }^{[26]}$ When the disease is in its maximum expression, erythema transforms into deep ulceration and pain is severe. Then, opioids and changes in diet can be necessary. The ulcers regress in 2-3 weeks after treatment is over leaving no scars. During their manifestation, they are covered by pseudomembrane. Their outline is not well defined. They prefer the buccal and labial mucosa, the lateral surface of the tongue [Figure 1], the floor of the mouth and the soft palate. ${ }^{[23]}$

Oral mucositis is handled by the physician following set guidelines. Many studies suggest several agents in the treatment and prevention of $\mathrm{OM}$ with varying results. Oral hygiene protocols recommend dental intervention before chemotherapy, which included the use of dental floss and oral rinses. Sterile water or physiologic saline solution seems to be more effective than chlorhexidine. In addition, rinses with povidone iodine reduce the severity of $\mathrm{OM}^{\left[{ }^{[27]}\right.}$ Anti-inflammatory agents, such as benzydamine, are used for both prevention and management of $\mathrm{OM}$. Intravenous immunoglobulins and histamine gels can be used to prevent OM. Cytoprotective drugs, such as amifostine, are thought to suppress ROS. Sucralfate has limited effectiveness on OM and is often followed by nausea, rectal bleeding, and multiple rectal disorders. Vitamin $\mathrm{E}$ acts as an antioxidant against ROS. Glutamine, on the other hand, is used for both prevention and treatment of OM. ${ }^{[22]}$ The use of allopurinol to prevent mucositis is controversial. Propantheline causes hypo-salivation, thus reducing mucosal exposure to agents in saliva. ${ }^{[28]}$

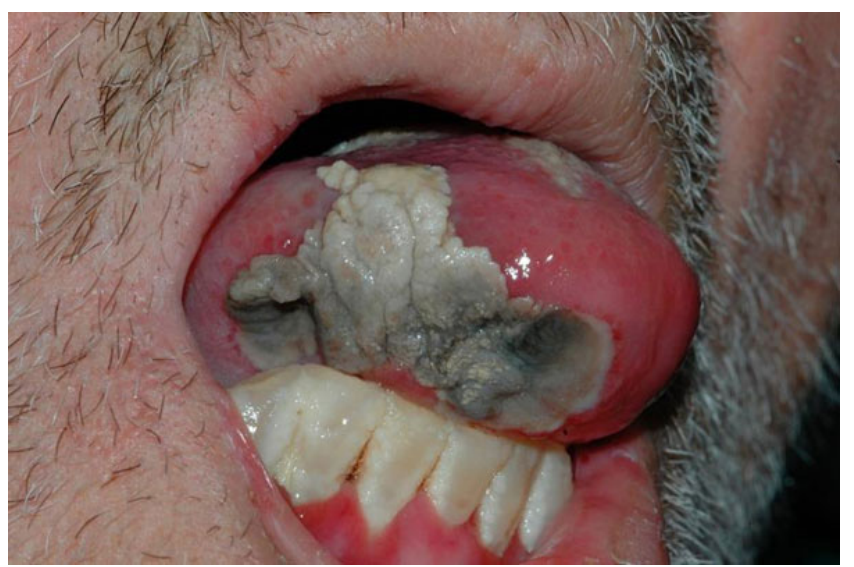

Figure 1: Tongue necrosis due to chemotherapy with a nucleoside metabolic inhibitor in a patient with acute myeloblastic leukaemia 
Anesthetics, such as xylocaine and lidocaine solutions, as well as analgesics such as morphine, are applied to relieve patient's pain. It is important to mention that a so-called "magic mouthwash" has been described, which consists of diphenhydramine, viscous lidocaine, bismuth subsalicylate, and corticosteroids. ${ }^{[29]}$

Recent studies have shown that only a few interventions are effective in the prevention and treatment of OM. Cryotherapy proves to be an effective choice for patients receiving chemotherapy. It causes local vasoconstriction, reducing mucosal blood flow and thus exposure of the mucosa to the agent. On the other hand, cryotherapy is contraindicated in patients treated with oxaliplatin, to eliminate the possibility of neurological side effects such as mandibular stiffness. ${ }^{[30]}$ It is recommended that cryotherapy 5-30 min before treatment with 5-fluorouracil can limit the mucositis symptoms. ${ }^{[31]}$ Granulocyte-colony stimulating factor (G-CSF) and granulocyte macrophage-colony stimulating factor (GM-CSF) may limit the extent and duration of mucositis. ${ }^{[22]}$ Palifermin intravenously is also a beneficial choice to prevent mucositis. Laser therapy seems to produce satisfying results in the treatment and prevention of $\mathrm{OM}$ in chemotherapy patients. Specific guidelines by the MASCC/ISOO of 2014 underline the proper characteristics of laser therapy (wavelength about $650 \mathrm{~nm}$, power setting $40 \mathrm{~mW}$ and a dose of $2 \mathrm{~J} / \mathrm{cm}^{2}$ at each square centimeter of tissue). ${ }^{[32]}$

In addition, new interventions offer a great deal of prevention of OM, thus discharging the chemotherapy patient from the painful and annoying side effects of mucositis. Zinc appears to favor wound healing and preservation of epithelial tissue integrity. It seems to increase re-epithelialization and acts against inflammation and bacterial development. According to certain reports, zinc sulfate may restrict the extent of OM. ${ }^{[33]}$ Moreover, a new lozenge was tested for its preventive action against OM. The lozenge consists of polaprezinc $(18.75 \mathrm{mg})$, sodium alginate $(0.05 \mathrm{~g})$, magnesium stearate $(0.005 \mathrm{~g})$, acesulfame potassium $(0.0015 \mathrm{~g})$ aspartame $(0.0015 \mathrm{~g})$, mannitol $(0.33 \mathrm{~g})$, cellulose $(0.4 \mathrm{~g})$, cornstarch $(0.05 \mathrm{~g})$, and a fragnase material $(0.01 \mathrm{~g})$. This suspension was orally administered at a dose of $5 \mathrm{~mL}$. It was rinsed for $2 \mathrm{~min}$ and then swallowed 4 times a day for a month. Polaprezinc suspension proved to be effective in preventing $\mathrm{OM}$ after high dose chemotherapy course. Polaprezinc is currently used as an antiulcer agent, with a protective action on mucosal cells against noxious stimuli and it presents anti-oxidant characteristics. The polaprezinc lozenge can be easily taken; thus, it is suitable for outpatients and hospitalized patients. ${ }^{[34]}$ The prevention management of mucositis is summarized in Table 1.

\section{Osteonecrosis of the jaws}

Osteonecrosis impairs the function of osteoclasts and osteoblasts which are the main types of cells that are closely related to bone health and repair. It appears after temporary or permanent impairment of the bone blood supply. ${ }^{[35]}$ Osteonecrosis can be caused by trauma (tooth extraction, periodontal procedures, biopsy), osteoporosis, malignancy, or certain types of medication. In the first stages, the lesions may remain asymptomatic for weeks, months, or even years. When inflammation invades the lesions, pain reveals itself. Tooth mobility, mucosal swelling, erythema, ulceration, paresthesia, or even damage to the associated part of the trigeminal nerve may be observed. ${ }^{[36]}$

Bisphosphonates are mainly responsible for the development of osteonecrosis of the jaws (ONJ) [Figure 2]. They are used as chemotherapy agents against bone metastases, malignant hypercalcemia, or malignant melanoma, and for the treatment of osteoporosis..$^{[2]}$ It is important to mention that sunitinib (a tyrosine kinase inhibitor) may increase the risk of bisphosphonate-related osteonecrosis of the jaws. ${ }^{[37]}$ The presence of ONJ can be intense in patients receiving sunitinib and bisphosphonates. Sunitinib was shown to be strongly related to mucositis, thus underlining the fact that the destruction of epithelium may be a crucial step in the development of ONJ.

There are several reviews regarding osteonecrosis due to bisphosphonates. These reviews present the current research and the international consensus on the diagnosis and management of ONJ. ${ }^{[38,39]}$

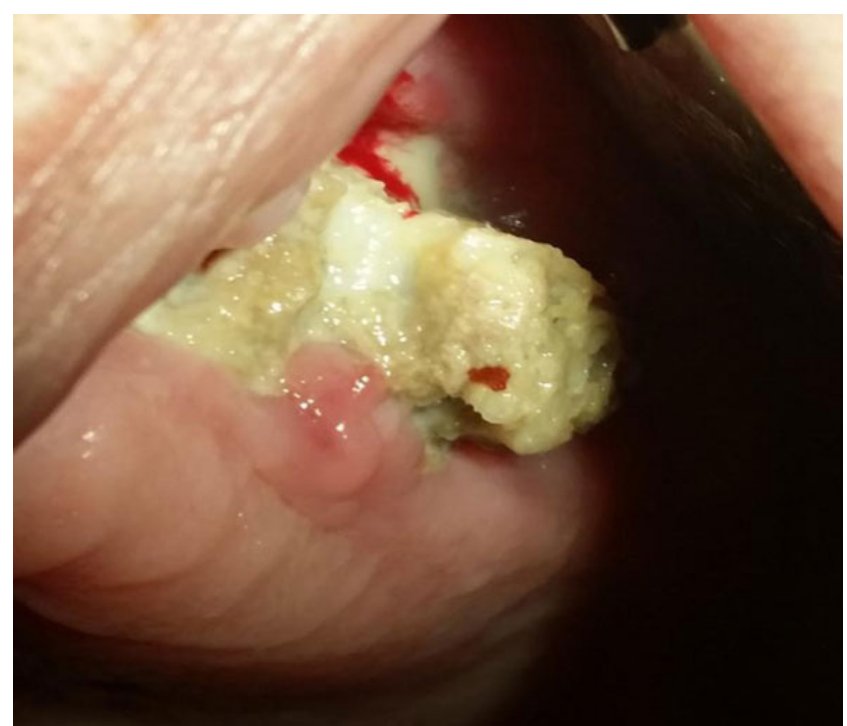

Figure 2: Osteonecrosis of the maxilla due to bisphosphonates 
Table 1: Prevention of oral mucositis

\begin{tabular}{|c|c|c|c|}
\hline Authors & Year & Prevention means & Type of article \\
\hline Potting et al. ${ }^{[27]}$ & 2006 & $\begin{array}{l}\text { Povidone iodine rinses, chlorhexidine, sterile water and } \\
\text { physiologic saline }\end{array}$ & Review \\
\hline Chavelli-Lopez et al..$^{[22]}$ & 2016 & $\begin{array}{l}\text { Benzidamine, Intravenous immunoglobulins, sucralfate } \\
\text { histamine gels, glutamine, amifostine, granulocyte colony } \\
\text { stimulating factor (G-CSF), granulocyte macrophage colony } \\
\text { stimulating factor (GM-CSF) }\end{array}$ & Review \\
\hline Scully et al. ${ }^{[28]}$ & 2006 & Allopurinol, propantheline & Review \\
\hline Chaveli-Lopez et al. ${ }^{[29]}$ & 2011 & $\begin{array}{l}\text { Mouthwash of: diphenhydramine, viscous lidocaine, bismuth } \\
\text { subsalicilate and corticosteroids }\end{array}$ & Review \\
\hline Clarkson et al. ${ }^{[31]}$ & 2010 & Cryotherapy & Review \\
\hline Lalla et al. ${ }^{[32]}$ & 2014 & Palifermin & Review \\
\hline Arbabi-Kalati et al. ${ }^{[33]}$ & 2012 & Zinc sulfate & Case report \\
\hline Hayashi et al. ${ }^{[34]}$ & 2016 & $\begin{array}{l}\text { Lozenge: polaprezinc, sodium alginate, magnesium stearate, } \\
\text { acesulfame potassium aspartame, mannitol, cellulose, } \\
\text { cornstarch, fragnase material }\end{array}$ & Case series \\
\hline
\end{tabular}

A detailed patient history and clinical examination remain the most sensitive diagnostic tools for ONJ. A clinical finding of exposed bone in the oral cavity for eight weeks or longer, despite appropriate therapy, is the distinctive diagnostic feature of ONJ. ${ }^{[38]}$ Radiographic features of ONJ remain relatively nonspecific. Imaging modalities, such as a CT, may be useful in delineating the extent of the disease, and are helpful in planning a surgical intervention. ${ }^{[38]}$

With respect to ONJ management, many factors may contribute to the planned treatment including age, gender, disease status, ONJ stage, lesion size, medication exposure, and medical/pharmacological comorbidities. ${ }^{[38]}$ How these variables influence the course of ONJ, and its treatment response are largely unknown. Clinical judgment should guide the individual treatment approach. In summary, in the absence of debilitating ONJ lesions, conservative therapy with optimal oral hygiene, topical antibiotic rinses, and systemic antibiotics are advised as needed for pain or infection. For non-responsive ONJ lesions, surgery is an option and includes ostectomy of the affected area with resection margins that extend into adjacent normal-appearing bone. Soft tissue closure should be tension-free with no underlying sharp edges of bone that could lead to a mucosal breakdown. ${ }^{[38]}$

\section{Infections}

Neutrophils represent $55-70 \%$ of the circulating white blood cells. They are able to identify and destroy invaders. Chemotherapy reduces their number causing neutropenia which in turn favors the development of infections. The oral cavity is a common sight of infections, often caused by bacteria, fungi, and viruses. ${ }^{[40]}$

\section{Bacterial}

Bacteria may be responsible for odontogenic infections. The usual symptoms are erythema, edema, and purulence. During neutropenia, it is common to observe a previously asymptomatic tooth (which has received successful endodontic treatment and has been radiographically checked), giving rise to symptoms of infection. ${ }^{[40]}$ Periapical infections affect maxillary posterior teeth and if severe perforate the Schneiderian membrane and lead to sinusitis. Elimination of the infection source and antimicrobial therapy for at least three to four weeks may be necessary. Clindamycin or amoxicillin with clavulanic acid are the drugs of choice accompanied by extraction or incision only when is inevitable. Periapical lesions left untreated may progress to osteomyelitis of the jaws. Pain, suppuration and even fistulae are common. Their management includes broad spectrum antibiotics. Rarely, the progression of the infection may cause cavernous sinus thrombosis and Ludwig angina. Then, immediate transfer to the nearest hospital and aggressive therapy with antibiotics are crucial and may save patients life..$^{[4]]}$

Periodontal disease is a common finding in chemotherapeutic patients [Figure 3]. The clinical picture is not characteristic of the disease. Pericoronitis often arises in the area of the third molars accompanied by ulceration, necrosis and severe pain. Necrotizing ulcerative gingivitis may coexist. Exposure of the bone may be possible in sites of previous periodontal lesions. Treatment includes scaling, extraction of the tooth, and antimicrobial therapy with penicillin, clindamycin, or metronidazole. ${ }^{[42]}$

Sialadenitis, especially of the parotid gland, may rarely be observed and may give rise to severe pain and swelling. Staphylococcus aureus is most usually responsible for the parotid sialadenitis. It is treated with amoxicillin and/clavulanic acid or clindamycin. ${ }^{[43]}$

Gram-positive cocci are often detected in neutropenic patients. Streptococcus viridans usually causes 
bacteremia. Streptococcus mitis causes toxicity leading to rash, hypotension, palmar desquamation, and acute respiratory syndrome. Vancomycin is often used to handle a severe bacteremia. In addition, prophylactic antimicrobial medication seems to limit the bacteremia. Broad spectrum antibiotics, such as quinolones, are often chosen by medical specialists. Modern therapies, including granulocyte colony stimulating factor and palifermin, decrease the duration of neutropenia and can reduce the extent of mucositis. ${ }^{[44]}$

As far as the management of bacterial infections, it is useful to mention that the treatment of dental and periodontal problems before chemotherapy, or throughout the whole course of the chemotherapy, reduces the incidence of oral complications associated with the procedure. ${ }^{[45]}$ Extraction is a favorable choice for teeth with a poor prognosis, but it is critical to take place at least ten days before the initiation of chemotherapy. ${ }^{[2]}$

\section{Fungal}

The persistence of neutropenia, due to chemotherapy, favors the development of fungal infections. The most common fungi are Candida and Aspergillus species. Zygomyces and endemic fungi, such as Histoplasma capsulatum, should also be considered as well as Fusarium species. Candida albicans is widely detected in such infections. ${ }^{[46]}$

Pseudomembranous, erythematous, and hyperplastic candidiasis, as well as the angular cheilitis, are usually present can cause dysgeusia and xerostomia, a burning sensation and a general oral discomfort. The

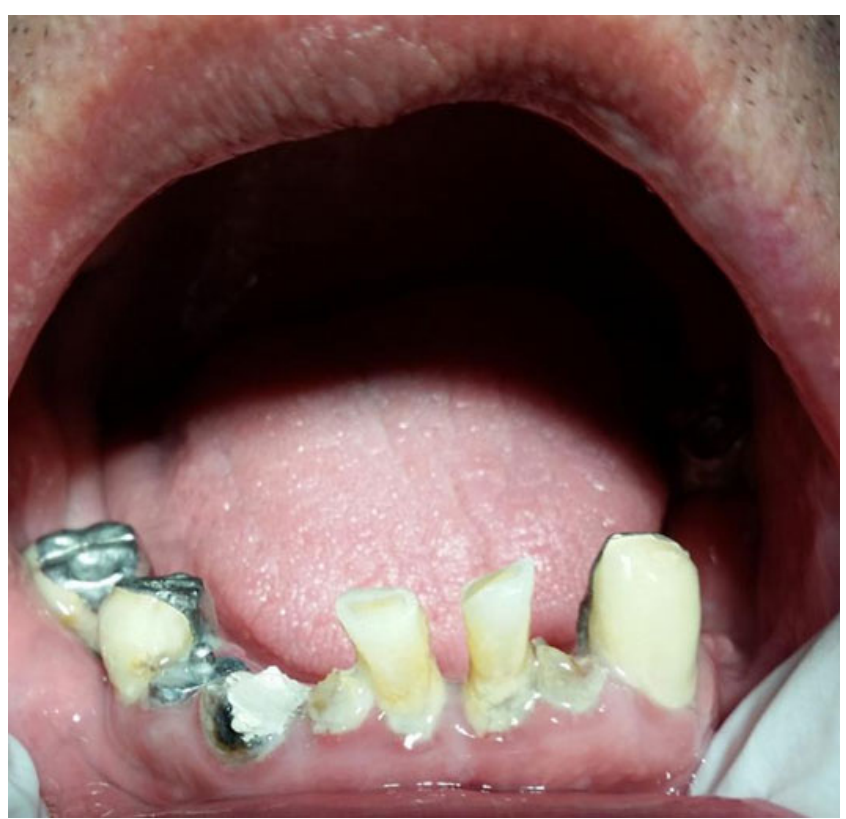

Figure 3: Periodontal disease due to chemotherapy pseudomembranous form is the most common. It clinically presents as papules which can be scratched away leaving areas of erythema. An important factor that favors the development of candidiasis is the impairment of salivary gland secretion. Saliva contains IgA, histatins, lysozyme, mucins, transferrin, lactoferrin, defensins, and secretory components. These factors have antimicrobial, fungistatic, and fungicidal action; moreover, they inhibit adhesion and multiplication of Candida species on the mucosa. The presence of mucositis is also can be an important risk factor for fungemia in chemotherapeutic patients. ${ }^{[47]}$

Treatment may be either topical or systemic. Oropharyngeal infections may be managed with clotrimazole or nystatin. Both agents influence permeability of the microorganisms' cell membrane which results in loss of several intracellular components. Clotrimazole also interacts with cytochrome P450. Both of the drugs contain dextrose and sucrose, and may increase blood glucose or cause dental caries. In case the patient wears removable dentures, the dentures should be disinfected in nystatin, chlorhexidine solution, or diluted sodium hypochloride for at least 20-30 min every day. The patient must not wear the dentures during the night. Systemic therapy requires the use of triazoles such as fluconazole or itraconazole. Itraconazole inhibits the cell membrane and interacts with P450 cytochrome. Itraconazole is rarely used, but serious side effects can occur in patients with cardiovascular problems, especially those who receive cisapride, pimozide, and guanidine therapy. ${ }^{[41]}$ Fluconazole, on the other hand, can be used on a prophylactic basis. Echinocandins (micafungin, or caspofungin), AmB formulations (amphotericin B) are agents used for severe refractory infections. Caspofungin is an effective drug against Aspergillus and Candida species. ${ }^{[48]}$

Fusarium species can cause disseminated infection associated with high mortality rates in immunocompromised patients receiving agents, such as alemtuzumab. Alemtuzumab is often responsible for the loss of $T$ cells, B cells, natural killer cells, and monocytes. Combination antifungal therapy seems to be efficient against disseminated infections. Amphotericin B and voriconazole for Fusobacterium solani; amphotericin $\mathrm{B}$ and caspofungin against $F$. solani and $F$. oxysporum can be used as combination therapy. Voriconazole and caspofungin, or voriconazole, and terbinafine are interesting combinations tested in vitro. ${ }^{[49]}$

Viral

Viruses replicate inside a host cell, multiply and 
invade other cells causing infection. Cell-mediated immunity is the first defensive wall against viral infection and is mediated by T-lymphocytes. Thus, immunocompromised patients are defenseless against viral invasions, such as patients receiving chemotherapy (invasion often follows reactivation of the virus) ${ }^{[2]}$

The herpetic infections with the most favorable HSV-1 subtype, are common in chemotherapy patients. The extent of the infection depends on the degree of immunosuppression. The lesions are more diffuse than those caused by radiotherapy. ${ }^{[42]}$ The lesions occupy the lower vermillion border and prefer areas of keratinized mucosa, such as the hard palate, gingiva, and tongue. They present as vesicles that rupture and leave ulcerations that heal, even without intervention, in 1 to 2 weeks. Lesions in immunocompromised patients are different from those of healthy individuals. They are larger and often solitary. The lesions can remain for months without antiviral therapy. A complete clinical examination, culture, and exfoliative cytology, accompanied by direct fluorescent antibody testing, ensure an immediate and valid diagnosis. In patients without antiviral prophylaxis, lesions can appear simultaneously with the initiation of chemotherapy. The first choice of treatment is acyclovir orally. A dose of $400-800 \mathrm{mg}$ is administered 5 times a day. In severe cases, intravenous acyclovir at a dose of $5-10 \mathrm{mg} / \mathrm{kg}$ every $8-12 \mathrm{~h}$ is an efficient scheme. Alternatively, valacyclovir or famciclovir can be used. ${ }^{[41]}$

The Varicella-zoster virus may present several weeks after the end of chemotherapy. Pain may occur without the appearance of lesions. The infection may progress to intraoral V. zoster, which causes severe discomfort, bacterial superinfection, scarring, and even death. In addition, post-herpetic neuralgia may be present in $6-18 \%$ of patients over 60 years old. They usually suffer from intense pain lasting more than 4 months after the 1st rash. ${ }^{[50]}$ Management of $\mathrm{V}$. zoster demands higher doses of acyclovir, valacyclovir, or famciclovir. ${ }^{[51]}$ The neuralgia treatment may require opioids, antidepressants, gabapentin, antidepressants, and local anesthetics. ${ }^{[52]}$ Cytomegalovirus and Epstein-Barr virus infections are associated with malignancies, infectious mononucleosis, oral hairy leukoplakia, various lymphoproliferative disorders, and transplantation procedures. There is not a reliable study that connects them with chemotherapy. ${ }^{[41]}$

\section{Lichenoid reactions}

A lichenoid reaction (LR) is a pathologic entity involving cutaneous or mucosal areas, or both of them simultaneously. The clinical appearance of oral lichen planus (OLP) with characteristic lesions of whitish reticular papules and erythematous erosions, ${ }^{[53]}$ and plaques in a reticular form accompanied by radiating striae may be present. ${ }^{[54]}$ Although LRs clinical presentation resembles that of OLP, LR has a close relationship with the causative agent. LR can disappear, either immediately after the agent's action is completed, or can persist. ${ }^{[55]}$ In addition, histologic examination reveals eosinophilic infiltration, prominent parakeratosis with acanthosis, and a vascular inflammation around the deep plexuses. These histologic features are absent in OLP. ${ }^{[56]}$

LRs usually are caused by several chemicals (e.g. amalgam) or by certain types of medications including chemotherapeutic agents [Figure 4]. Imatinib mesylate is a tyrosine kinase inhibitor that is a first choice agent against chronic myeloid leukemia. It impairs CD117, c-kit, or platelet derived tyrosine kinases. ${ }^{[56]}$ Imatinib administration can be accompanied by several side effects, such as periorbital edema, Steven-Johnson syndrome, pityriasis rosea, erythroderma, myalgia, diarrhea, exfoliative dermatitis, or edema of the legs. ${ }^{[57]}$ It is responsible for lichenoid lesions in the oral mucosa, skin, or nails. ${ }^{[5,56,58]}$

Suggestions have been expressed concerning the pathogenesis of LRs and LRs relationship with chemotherapy. Imatinib is responsible for the altered expression of epidermal markers. ${ }^{[57]}$ The expression of CK6 in the supra-basal layer of the mucosa indicates tissue impairment. This impairment may be associated with epithelial proliferation triggered by growth factors, leading to eruptions with the characteristics of lichenoid reactions caused by medications. Lichen planus is the result of an autoimmune process mediated by cd 4 and cd8

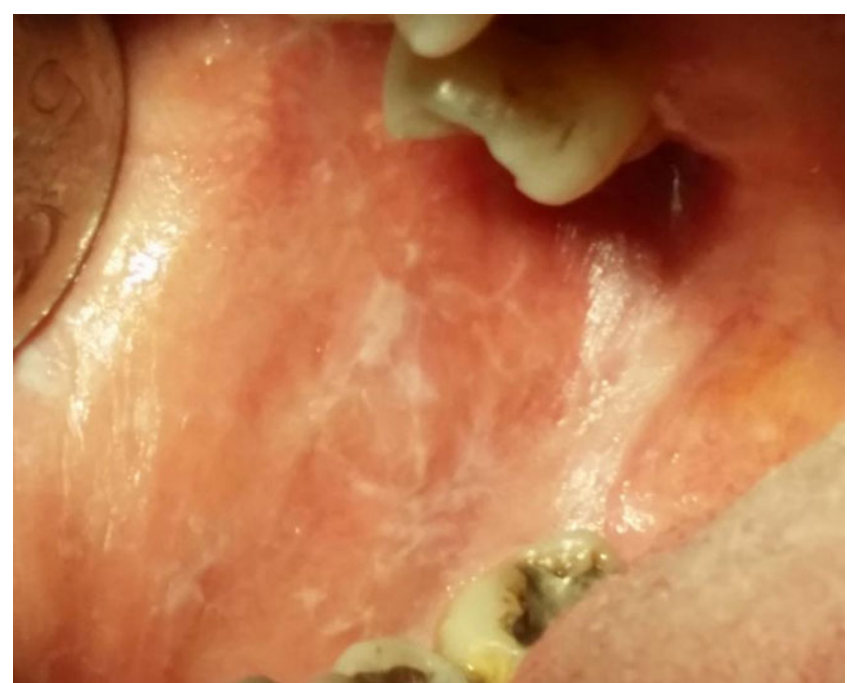

Figure 4: Lichenoid reaction of the buccal mucosa due to chemotherapy 
lymphocytes, and lymphokines. These are produced by cd8 lymphocytes which alter the dermal-epidermal junction. At the same time, an inflammatory infiltrate destroys keratinocytes that express several antigens. These antigens are thought to be of pharmacological or viral origin. All these can justify the hypothesis that the lichenoid reaction lesions may be related to altered expression of epidermal markers because of the imatinib. ${ }^{[56]}$

The management of $L R s$ requires the discontinuation of the causative agent. If the agent cannot be substituted or stopped, corticosteroids can be used. Prednisolone taken orally followed by topical corticosteroids have shown satisfactory results. ${ }^{[58]}$

\section{Dental anomalies}

Children who receive chemotherapy before the age of five can present extensive damage in their dentition. This damage underlines the fact that the developing dentition is more vulnerable to damage from chemotherapy. Chemotherapy is responsible for certain dental anomalies such as microdontia, enlargement of the dental pulp chamber, tooth developmental retardation, or root malformations. The chemotherapy causes qualitative defects of the teeth. The extent of the defects depends on the type of the agent and the half-life of the drug regiment. It is also related to the number of cells invaded in the cell cycle, as well as the age of the patient at the initiation of the therapy. ${ }^{[59]}$

Enamel hypoplasia and discoloration are the most common defects. Hypoplasia is the result of ameloblastic damage as far as it concerns their reproductive and secretory function, their membrane permeability and calcium exchange across the membrane. These alterations cause enamel opacities. Disturbances in the development and proper positioning of Hertwig's sheath lead to displacement of the floor of the pulp and the bifurcation area. This situation is mostly observed in molars but can be diagnosed in premolars. Repeated high doses of cytotoxic drugs can cause root agenesis. Additionally, the defective secretory function of microtubules, as well as alterations in intra- and intercellular connections, result in an abnormal odontoblastic function. Invasive high dose chemotherapy may cause teeth agenesis. ${ }^{[60]}$

Hypodontia is the absence of one or more teeth. Hypodontia is due to high repetitive administration of chemotherapy agents. It is the result of defects in the initial phase of the tooth formation cycle. Failure of the dental lamina or tooth bud formation causes abnormal development. This failure may lead to hypodontia. ${ }^{[59]}$
Studies in animals revealed dental anomalies caused by agents such as vinblastine, vincristine, doxorubicin, and cyclophosphamide. Cyclophosphamide acts as an alkylating agent. It inhibits cell division by cross-linking the guanine bases of DNA resulting in mutations. ${ }^{[0]}$

\section{Hyposialia and xerostomia}

Chemotherapy usually impairs salivary gland function. This disturbance is temporary and reversible. However, it causes discomfort, affects the speech, and difficulties with chewing. The patient's quality and quantity of saliva is altered. Increased levels of amylase and peroxidase are observed. The simultaneous decrease in the amount of $\lg A$ and $\lg G$ accompany the chemotherapy. Thus oral mucosa becomes prone to trauma and oral mucositis. ${ }^{[2]}$ Salivary functions such as lubrication, moistening, and antimicrobial properties are impaired. It has been recorded that the unstimulated salivary flow rates increase in patients suffering from oral ulceration throughout the chemotherapy course, probably as a result of nociceptive oral stimulation. ${ }^{[61]}$

According to another study, chemotherapy seemed to affect basal and stimulated saliva in a different manner. Basal saliva $\mathrm{pH}$ presented without changes, while the stimulated saliva $\mathrm{pH}$ became acidic. This fact, along with a decrease in the amount of salivary flow altered healthy flora. Moreover, electrolytic changes were detected. An increase in $\mathrm{N}^{+}$and $\mathrm{K}^{+}$led to damage in the salivary duct transport mechanisms during ion rearrangement. Urea was also increased. All these factors, favor the rise of pathogenic bacteria and thus periodontal disease. Agents such as adriamycin, cyclophosphamide, and fluorouracil can cause reduction of saliva flow leading to taste disturbances and a burning sensation. Defensive properties are impaired as well, due to the lack of lysozyme, lactoferrin, immunoglobulin, and antibacterial substances. ${ }^{[62]}$

Other studies have shown that saliva secretion returns to physiologic levels approximately twelve months after the chemotherapy is completed. ${ }^{[63]}$

The consumption of a large amount of water in combination with sugar-free sweets and chewing gums proves to be useful in the management of hyposialia and xerostomia. In more serious situations, pilocarpine (keep in mind the possible side effects of pilocarpine), bromhexine, or bethanechol can be used. ${ }^{[2]}$

\section{Taste changes}

Taste disturbancesare widely detected in patients undergoing chemotherapy. Although they are not lethal, taste disturbances may cause a great deal of discomfort. As a result, patients may refuse the 
intake of food which may delay the patient's recovery. Pathophysiology of dysgeusia includes damage of selective cranial nerves (VII, IX, X), the oral mucosa, or the taste buds. ${ }^{[64]}$ The defect in taste buds is caused by zinc deficiency; moreover, dysgeusia may be associated with vitamin D deficiency. ${ }^{[65]}$ Several studies do not relate taste alterations to a decrease in salivary flow rates or oral dryness. ${ }^{[66]}$ The diagnosis of taste disturbances is verified by using procedures such as electrogustometry, whole mouth gustatory testing, or magnetoencephalography. ${ }^{[67]}$

In several studies, the prevalence of dysgeusia due to chemotherapy was noted to be $39 \%$. According to the same study, $38 \%$ of the patients with phantogeusia and parageusia experienced a salty taste, $22 \%$ mixed sensation such as bitter-salty or sweet-sour taste. ${ }^{[68]}$ Most common changes include a metallic taste, loss of taste acuity, or bitterness when the administration of an agent is taking place. ${ }^{[69]}$ Dysgeusia lasts for a few weeks after the initiation of the treatment. ${ }^{[2]}$ Generally, disturbances retreat in a few hours, days, weeks, or even months after chemotherapy is initiated. Dysphagia is a common side effect after the administration of cytotoxic agents. This implies that swallowing difficulties occur during the oropharyngeal or esophageal stages of swallowing. ${ }^{[70]}$

Agents usually associated with taste defects are cisplatin, doxorubicin, 5-fluorouracil, levamisole, doxecatel, paclitaxel, cyclophosphamide, or carboplatin. ${ }^{[64]}$ Alterations in taste have been recorded in $26 \%$ of the patients receiving crizotinib. The replacement of crizotinib with alectinib, which is also an alkylating inhibitor, showed promising results. The reduction of the dose or discontinuation of crizotinib was considered necessary in $6.5 \%$ of the patients. ${ }^{[71]}$

\section{Bleeding}

Cytotoxic medications negatively affect bone marrow cells. This deleterious effect can lead to thrombocytopenia. This bone marrow suppression can be responsible for excessive bleeding. More specifically, patients present with petechiae, hematomas, or ecchymoses. Ecchymoses can reveal a low platelet count during chemotherapy. A platelet count under $50,000 / \mathrm{mm}^{3}$ is a contraindication for tooth extraction or other invasive procedures dangerous. A platelet count under $20,000 / \mathrm{mm}^{3}$ increases the risk of excessive bleeding, especially throughout the manifestation of gingivitis. Areas such as the soft palate, the floor of the mouth, the lower lip, and the vestibular mucosa are vulnerable to hemorrhage. ${ }^{[63]}$

Special care should be used not to alter the blood clots to avoid bleeding. Several types of medications are used to reduce bleeding. Vasoconstrictors such as epinephrine are the drugs of choice. Mucoadherent protectors such as cyanoacrylate can seal the bleeding site. In addition, thrombin and hemostatic collagen can organize and stabilize the clots. ${ }^{[2]}$

\section{Neurotoxicity}

Agents such as vinblastine and vincristine are associated with neurotoxicity. This neurotoxicity can present as severe deep pain in the mandible. The pain retreats a week after the chemotherapy course are completed. Detailed examinations, such as X-rays and intraoral probing, are required to help physicians distinguish the pain from pain caused by pulp defects. Most of the time, dental sensitivity is observed weeks or months after chemotherapy. Topical fluorides or special desensitizing toothpaste may prove to be efficient in restricting the symptoms. ${ }^{[2]}$

\section{Oral hyperpigmentation-melanosis}

Imatinib therapy can produce cutaneous and mucosal depigmentation or hyperpigmentation ${ }^{[72]}$ which proved to be dose related and reversible when administration ceases. Imatinib effects c-kit, which is a tyrosine kinase receptor with regulatory action on melaninogenesis. C-kit has been detected in mesenchymal cells in the oral cavity and dental pulp. ${ }^{[73]}$

Imatinib is responsible for the overstimulation of melaninogenesis in certain cutaneous and mucosal areas. It appears that imatinib binds to several receptors in the skin activating or inhibiting melaninogenesis. ${ }^{[74]}$ Reports have described bluishbrown pigmentation on the hard palate ${ }^{[75]}$ and similar lesions have been observed in the gingival, the teeth, and the perioral region. ${ }^{[76]}$

\section{Steven-Johnson syndrome - toxic epidermal necrolysis}

Toxic epidermal necrolysis (TEN) and StevenJohnson syndrome (SJS) are different forms of the same pathologic entity. They are rare, life-threatening conditions involving both the cutaneous and mucosal membranes. ${ }^{[77]}$ They are distinguished by the degree of body surface area exfoliation. SJS is limited to less than $10 \%$ of the total body surface area; whereas, TEN exceeds $30 \%$ of the total body surface area. Exfoliation implies a positive Nikolsky sign (epidermal detachment caused by slight rubbing of the skin) and is the result of the destruction of keratinocytes by apoptosis. ${ }^{[78]}$ Apoptosis, in turn, is mediated by the interaction of Fas-FasL receptor ligand with the granulysin's cytolytic action. Clinically, they are characterized by the presence of areas of erythema and macules, which later produces extensive exfoliation. ${ }^{[79]}$ The diagnosis is confirmed by histopathology. The histopathology 
reveals extensive full-thickness necrosisof the epidermis. ${ }^{[78]}$

Several types of medication seem to be responsible for the appearance of TEN-SJS. Among these are several chemotherapeutic agents, such as imatinib, cetuximab, 5-fluorouracil, rituximab or bortezomib. ${ }^{[8]}$ Lenalidomide is a bioavailable analog of thalidomide and is an ideal choice for multiple myeloma. This can be used alone or in combination with dexamethasone. Unfortunately, lenalidomide is associated with the pathogenesis of SJS. ${ }^{[78]}$

The management of TEN-SJS is complicated. Corticosteroids can contribute to the maintenance of vascular integrity and the impairment of expression of leukocyte adhesion molecules. Corticosteroids suppress immunologic functions of cytotoxic T-lymphocytes and macrophages. ${ }^{[81]}$ Their efficacy has been controversal. ${ }^{[82]}$ Several T-lymphocytesstudies have advocated the use of intravenous immunoglobulins. The studies underline immunoglobulins tolerability and low toxicity. Immunoglobulins should be given with caution in patients with renal failure, cardiac insufficiency, IgA deficiency or previous episodes of thromboembolism. ${ }^{\left[{ }^{83]}\right.}$ Cyclosporine has also been used to treat TEN-SJS. Patients demonstrated quicker re-epithelialization and fewer cases of death and multi-organ failure. ${ }^{84]}$ Recently, new treatments have been tried. A single dose of $5 \mathrm{mg} / \mathrm{kg}$ infliximab (chimeric anti-TNF- $\alpha$ antibody) has been used. The disease progression was blocked within $24 \mathrm{~h}$; whereas, epithelial recovery was completed within 5 days. ${ }^{[85]}$ Plasmapheresis/plasma exchange has been attempted, but results were not able to provide safe conclusions as to its therapeutic potential. ${ }^{[78]}$

\section{DENTAL INTERVENTIONS AND CHEMOTHERAPY}

\section{Treatment before chemotherapy}

The role of the dentist in the care of a patient before, during, and after the chemotherapy course is crucial. Before any procedure takes place, the oncologist should inform the dentist of the patients current health status, the characteristics of the pathologic entity, and the antineoplastic therapy to be prescribed. ${ }^{[2]}$ A thorough examination which consists of a dental history, a radiographic baseline (including periapical, bitewing and panoramic radiographs), a periodontal and endodontic evaluation, and a prognosis of the existing restorations is completed. ${ }^{[86]}$ Recognition of potentially malignant findings providing signs and symptoms is critical. ${ }^{[87]}$ Investigations, such as quantitative sialometry, are very useful and can help evaluate, predict, and manage the potential xerostomia and hyposalivation. ${ }^{[88]}$

In addition, the dentist should take into consideration a number of aspects that will help him/her organize a suitable and successful treatment plan. In particular, he/ she must realize that odontogenic infections are rare, but may give rise to bacteremia in immunosuppressed patients. All possible sources of dental inflammation should be addressed. Moreover, the periodontal index $(\mathrm{PI})$, gingival index $(\mathrm{Gl})$ in combination with the decayed, missing and filled teeth/surfaces (DMFT/S) can provide a clear indication of patient's oral hygiene, and be a reliable predictive indicator of future disease. Finally, the dentist organizes his/her treatment plan, according to the time available before the initiation of the chemotherapy, keeping in mind the patient's immune status. ${ }^{[89]}$

The patient must then be counseled and be made aware of all the possible oral complications caused by chemotherapy. This should include the patient's current dental hygiene status, and the procedures he/she is going to follow before, during, and after chemotherapy.

Dental procedures taking place prior to chemotherapy should be performed carefully by the clinician. Careful denture fitting and the adjustment of a traumatic prosthesis should be completed. Specific instructions concerning oral hygiene and caries prevention are given to the patient. ${ }^{[90]}$ Tartar removal, dental fluoridation, and chlorhexidine are highly recommended. Chlorhexidine provides bactericidal activity against gram-positive and gram-negative bacteria by damaging the cell membrane and cellular enzymes. Chlorhexidine $0.12 \%$ has been found to reduce bleeding and plaque accumulation, as well as a reduction in Streptococcus mutans concentrations in saliva. ${ }^{\left[{ }^{[9]}\right.}$ In children, fissure sealing and crack restoration in recently erupted teeth, especially molars and premolars, are mandatory. ${ }^{[2]}$ Endodontic care is performed under specific guidelines, for reversible pulpitis, only caries control is advised. In cases of irreversible pulpitis, initial biomechanical preparation of the canal is suggested. However, in chronic periapical situations, endodontic procedures are performed when there is a time interval of 7 days between completion of endodontic therapy and the initiation of chemotherapy. In acute periapical infections, the choice of endodontic treatment vs. extraction depends on the general health status of the patient. ${ }^{[89]}$ Teeth with a poor or questionable prognosis should be extracted. Extractions should be performed 2-3 weeks before the onset of chemotherapy. ${ }^{[86]}$ The removal of a tooth should be followed by primary 
wound closure and suturing. Intra-alveolar hemostatic agents should be avoided. Platelet transfusion is required if the platelet count is under $40,000 / \mathrm{mm}^{3}$. Antibiotic prophylaxis is also necessary if granulocytes are under $2,000 / \mathrm{mm}^{3}$. Moreover, limited invasive procedures should take place at least 2 weeks before chemotherapy, while major surgery should be completed 4-6 weeks before the onset of the chemotherapy. ${ }^{[88]}$ When patients are about to receive bisphosphonates, the same precautions must be taken. In addition, trauma from an extraction, or any other invasive procedure should be minimal. This ensures a quick and ideal result. Preventive treatment, or the postponement of traumatic procedures, can reduce the risk of osteonecrosis of the jaws. ${ }^{[91,92]}$ When extensive surgery precedes chemotherapy in cases of head and neck pathology, obturators are often required to restore anatomy and crucial functions, such as speech, mastication, and breathing ${ }^{[86]}$ The dental management before chemotherapy is summarized in Table 2 .

\section{Dental treatment during chemotherapy}

Dental treatment during chemotherapy should be avoided unless it is urgently necessary. Extractions and other invasive procedures should be postponed. Throughout chemotherapy, the dentist must be aware of the degree of immunosuppression of the patient. Dental hygiene must be preserved at a satisfying level, and cariogenic food must be avoided. ${ }^{[88]}$ Dental health can be achieved by fluoridation and the use of chlorhexidine. ${ }^{[2]}$ Tooth brushing can take place when the oral pain resolves, whereas, some patients can only tolerate swabbing with a special finger brush. Toothpaste containing $1,450 \mathrm{ppm}$ sodium fluoride is recommended. ${ }^{\text {900] }}$

Complications of chemotherapy, such as xerostomia and mucositis, must be managed at the time of their presentation. Regarding mucositis, there are reports of the use of ice chips or a benzydamine hydrochloride oral rinse prior to chemotherapy. ${ }^{[93]}$ Pain must be addressed as well, which requires extra caution because of the immunosuppression caused by antineoplastic medication may result in liver toxicity, nephrotoxicity, ototoxicity or gastrointestinal disorders, favored by the administration of various drugs. Therefore, the analgesics that are chosen are paracetamol or metamizole. Antibiotic administration is useful when needed. The dosage should be adjusted according to creatine clearance values, especially for patients with kidney impairment. Non-steroidal antiinflammatory (NSAI) drugs are forbidden because of their harmful interactions. A combination of an NSAI with corticosteroids may increase the risk of gastric ulcers. NSAls with methotrexate increases the risk of hemorrhage, and NSAls with cyclosporine can multiply the risk of nephrotoxicity. ${ }^{[2]}$ Candidiasis usually rises during chemotherapy; therefore, systemic antifungals are used to treat outbreaks. ${ }^{[0]}$

Invasive, traumatic dental procedures should be abandoned. Thus, no extraction or even minimal surgical procedures should be performed. Tooth scaling and root planning are contraindicated due to the high risk of infection. ${ }^{[90]}$ In case the patient has received bisphosphonates, all of the treatments should be carefully monitored to avoid trauma or frictional ulcers. Dentures should be removed if they are even minimally traumatic, and the patient must be re-examined after 7-10 days. Emergency procedures should be covered by antibiotics. Tooth extractions should take place only when there is an absolute need. Extractions should be followed by socket curettage, removal of any debris, and finally suturing. ${ }^{[94]}$ The dental management during chemotherapy is summarized in Table 3.

\section{Dental treatment after chemotherapy}

After chemotherapy, dental treatment is planned by consulting the oncologist. The treatment is designed to remove the remaining foci of infection and to restore esthetic and any functional impairment. ${ }^{[2]}$ As side effects after the completion of the chemotherapy reside, the patient can eat and drink small frequent meals. These meals must be composed of a high-

Table 2: Dental interventions before chemotherapy

\begin{tabular}{|c|c|c|c|}
\hline Authors & Year & Type of therapy & Type of article \\
\hline Lopez et al. ${ }^{[2]}$ & 2011 & $\begin{array}{l}\text { Information of the dentist: health status, course, type of } \\
\text { malignancy, fissure sealing, crack restoration in recently } \\
\text { erupted teeth }\end{array}$ & Review \\
\hline Barclay and Turani ${ }^{[86]}$ & 2010 & $\begin{array}{l}\text { Radiographic control, anamnesis, periodontal and } \\
\text { endodontic status evaluation, extractions }\end{array}$ & Review \\
\hline Epstein et al. ${ }^{[87]}$ & 2014 & Signs and symptoms of potentially malignant sites & Review \\
\hline Caribé-Gomes et al. ${ }^{[88]}$ & 2003 & Quantitative sialometry & Review \\
\hline Hong et al. ${ }^{[89]}$ & 2010 & $\begin{array}{l}\text { Removal of all sites of inflammation, periodontal index, } \\
\text { gingival index, tartar removal, dental fluorization, } \\
\text { chlorhexidine use, endodontic care }\end{array}$ & Review \\
\hline McCaul $^{[90]}$ & 2012 & $\begin{array}{l}\text { Denture fitting, readjustment of traumatic prostheses, } \\
\text { instruction for hygiene }\end{array}$ & Review \\
\hline
\end{tabular}


Table 3: Dental interventions during chemotherapy

\begin{tabular}{lllc}
\hline Authors & Year & Type of therapy & Type of article \\
\hline${\text { Lopez et al. }{ }^{[2]}}^{2011}$ & $\begin{array}{l}\text { Fluorization, chlorhexidine; paracetamol or } \\
\text { metamizol; antibiotic }\end{array}$ & Review \\
Epstein et al. ${ }^{[93]}$ & 2001 & $\begin{array}{l}\text { Xerostomia, mucositis management, ice chips, } \\
\text { benzydamine hydrochloride rinse }\end{array}$ & $\begin{array}{c}\text { Double-blind, placebo-controlled } \\
\text { clinical trial } \\
\text { McCaul }\end{array}$ \\
Campisi et al. $^{[94]}$ & 2012 & $\begin{array}{l}\text { Systemic antifungals } \\
\text { Review }\end{array}$ \\
\hline
\end{tabular}

Table 4: Dental interventions after chemotherapy

\begin{tabular}{|c|c|c|c|}
\hline Authors & Year & Type of therapy & Type of article \\
\hline Lopez et al. ${ }^{[2]}$ & 2011 & $\begin{array}{l}\text { Consulting oncologist, remove remaining foci of } \\
\text { infection, restore esthetic, functional impairment }\end{array}$ & Review \\
\hline McCaul ${ }^{[90]}$ & 2012 & $\begin{array}{l}\text { Advices: diet, chlorhexidine, high concentration } \\
\text { fluoride toothpaste, no dentures ( } 1 \text { year). In great need } \\
\text { construction } 4-6 \text { months after therapy }\end{array}$ & Review \\
\hline Barclay and Turani $i^{[86]}$ & 2010 & Regular dental control & Review \\
\hline Caribé-Gomes et al. ${ }^{[88]}$ & 2003 & $\begin{array}{l}\text { Extractions should be avoided, only in great need, } \\
\text { under antibiotics ( } 7-15 \text { days), hyperbaric oxygen } \\
\text { before-after. Regular reexamination ( } 1 / \text { month/1st } \\
\text { trimester, } 1 / 3 \text { months, } 1 / 6 \text { months) }\end{array}$ & Review \\
\hline
\end{tabular}

calorie diet or even sweets in order to preserve the patients' weight at a desirable level. However, this must take place under the close supervision of the dentist to monitor the oral hygiene to preserve dental and oral health. High concentration fluoride toothpaste is recommended, as well as chlorhexidine rinses every night for at least 3 weeks. The latter must be repeated every 3 months. ${ }^{[90]}$

Complications arising from chemotherapy must be managed in the most effective fashion. The patient should be regularly checked by their dentist, especially in the first few months. ${ }^{[86]}$ Extractions and other invasive procedures should be avoided for at least 1 year. However, if procedures cannot be postponed, precautions must be taken. The most important precaution is antibiotic coverage. The antibiotic coverage should be initiated $48 \mathrm{~h}$ before the procedure and continue for 7-15 days. Hyperbaric oxygen before and after extractions is recommended. ${ }^{[88]}$ Denture use should be avoided for 1 year. If this is not possible, the construction of the dentures should be postponed for 4-6 months following the chemotherapy. ${ }^{[00]}$

Moreover, in patients who have received intravenous bisphosphonates, special considerations must be addressed. When placing implants, the risk of bisphosphonate-related osteonecrosis of the jaw is significant. This condition is different in the patients who have had implants placed prior to the initiation of the bisphosphonates. ${ }^{[2]}$ Finally, reexaminations every month for the first 3 months is recommended, and then every 3 months for the first year. Mandatory examinations can then be extended to every 6 months for 3 years. ${ }^{[88]}$ The dental management after chemotherapy is summarized in Table 4.

In conclusion, chemotherapy can be associated with multiple side effects which affect the patient's quality of life. As it becomes well understood, most of these side effects cannot be avoided. Several preventive measures are taken in order to limit their expression. Nevertheless, most cancer patients experience difficult situations. The oral cavity is a usual site of discomfort and pain caused by chemotherapy, making dentist's contribution to patient's relief extremely important.

\section{Authors' contributions}

Manuscript's preparation: A. Poulopoulos, P. Papadopoulos

Manuscript's review: A. Poulopoulos, D. Andreadis

Concept design: A. Poulopoulos, D. Andreadis

Literature search: A. Poulopoulos, P. Papadopoulos

\section{Acknowledgments}

We thank Dr. Jon Wagner for his contribution in language editing.

\section{Financial support and sponsorship None.}

\section{Conflicts of interest}

There are no conflicts of interest.

\section{Patient consent \\ Obtained.}

\section{Ethics approval \\ Obtained.}




\section{REFERENCES}

1. Tannock IF, Hill RP, Bristow RG, Harrington L. The Basic Science of Oncology. 5th ed. New York: McGraw Hill Education; 2013. p. 393-419.

2. Lopez BC, Esteve CG, Perez MGS. Dental treatment considerations in the chemotherapy patient. J Clin Exp Dent 2010;3:31-42.

3. López-Galindo MP, Bagán JV, Jiménez-Soriano Y, Alpiste F, Camps C. Clinical evaluation of dental and periodontal status in a group of oncological patients before chemotherapy. Med Oral Patol Oral Cir Bucal 2006;11:E17-21.

4. Khan SA, Wingard JR. Infection and mucosal injury in cancer treatment. J Nat Cancer Inst Monogr 2001;(29):31-6.

5. Epstein JB, Tsang AH, Warkentin D, Ship JA. The role of salivary function in modulating chemotherapy-induced oropharyngeal mucositis: a review of the literature. Oral Surg Oral Pathol Oral Radiol Endod 2002;94:39-44.

6. Matesich SM, Shapiro CL. Second cancers after breast cancer treatment. Semin Oncol 2003;30:740-8.

7. Pfuhler S, Fellows M, van Benthem J, Corvi R, Curren R, Dearfield K, Fowler P, Frötschl R, Elhajouji A, Le Hégarat L, Kasamatsu T, Kojima H, Ouédraogo G, Scott A, Speit G. In vitro genotoxicity test approaches with better predictivity: summary of an IWGT workshop. Mutat Res 2011;723:101-7.

8. Khouri S, Kotliroff A, Lishner M, Amital H. Imatinib-induced agranulocytosis in a patient with chronic myelogenous leukemia in remission. Isr Med Assoc J 2008;10:320-1.

9. Hadland BK, Longmore GD. Erythroid- stimulating agents in cancer therapy: potential dangers and biologic mechanisms. $J$ Clin Oncol 2009;27:4217-26.

10. Dere E, Anderson LM, Hwang K, Boekelheide K. Biomarkers of chemotherapy-induced testicular damage. Fertil Steril 2013;100:1192-202.

11. Sheikhi MA, Ebadi A, Talaeizadeh A, Rahmani H. Alternative methods to treat nausea and vomiting from cancer chemotherapy. Chemother Res Pract 2015;2015:818759.

12. Gurumurthi R, Nimmagadda RB, Mohan S. Docetaxel-induced hand and foot syndrome in a patient with metastatic breast carcinoma. Indian J Dermatol 2013;58:380-2.

13. Chen ZI, Ai DI. Cardiotoxicity associated with targeted cancer therapies. Mol Clin Oncol 2016;4:675-81.

14. Bui N, Wong-Sefidan I. Reactivation of hepatitis B virus after withdrawal of erlotinib. Curr Oncol 2015;22:430-2.

15. Sioka C, Kyritsis AP. Central and peripheral nervous system toxicity of common chemotherapeutic agents. Cancer Chemother Pharmacol 2009;63:761-7.

16. Giglio P, Gilbert MR. Neurologic complications of cancer and its treatment. Curr Oncol Rep 2010;12:50-9.

17. Fantini M, Gianni L, Tassinari D, Nicoletti S, Possenti C, Drudi F, Sintini M, Bagli L, Tamburini E, Ravaioli A. Toxic encephalopathy in elderly patients during treatment with capecitabine: literature review and a case report. J Oncol Pharm Pract 2011;17:288-91.

18. Iżycki D, Niezgoda A, Kaźmierczak M, Nowak-Markwitz E. Chemotherapy-induced peripheral neuropathy-epidemiology and pathogenesis. Ginekol Pol 2016;87:293-9.

19. Graeppi-Dulac J, Vlaeminck-Guillem V, Perier-Muzet M, Dalle S, Orgiazzi J. Endocrine side-effects of anti-cancer drugs: the impact of retinoids on the thyroid axis. Eur J Endocrinol 2014;170:R253-62.

20. Dreno B, Bensadoun RJ, Humbert P, Krutmann J, Luger T, Triller R, Rougier A, Seite S. Algorith for dermocosmetic use in management of cutaneous side effects associated with targeted therapy in oncology. $J$ Eur Acad Dermatol Venereol 2013;27:1071-80.

21. Napeñas JJ, Brennan MT, Bahrani-Mougeot FK, Fox PC, Lockhart
PB. Relationship between mucositis and changes in oral microflora during cancer chemotherapy. Oral Surg Oral Pathol Oral Radiol Endod 2007;103:48-59.

22. Chavelli-Lopez B, Bagan-Sebastian JV. Treatment of oral mucositis due to chemotherapy. J Clin Exp Dent 2016;8:e201-9.

23. Al-Ansari S, Zecha JA, Barasch A, de Lange J, Rozema FR, RaberDurlacher JE. Oral mucositis induced by anticancer therapies. Curr Oral Health Rep 2015;2:202-11.

24. Sonis ST. A biological approach to mucositis. London: Springer Healthcare; 2012. p. 7-13.

25. Bian L, Han G, Zhao CW, Garl PJ, Wang XJ. The role of Smad7 in oral mucositis. Protein Cell 2015;6:160-9.

26. Chaveli-López B. Oral toxicity produced by chemotherapy: a systematic review. J Clin Exp Dent 2014;6:e81-90.

27. Potting CM, Uitterhoeve R, Op Reimer WS, Van Achterberg T. The effectiveness of commonly used mouthwashes for the prevention of chemotherapy-induced oral mucositis: a systematic review. Eur $J$ Cancer Care (Engl) 2006;15:431-9.

28. Scully C, Sonis S, Diz PD. Oral mucositis. Oral Dis 2006;12:229-41.

29. Chaveli López B, Gavaldá Esteve C, Sarrión Pérez MG. Dental treatment considerations in the chemotherapy patient. J Clin Exp Dent 2011;3:e31-42.

30. Worthington HV, Clarkson JE, Bryan G, Furness S, Glenny AM, Littlewood A, McCabe MG, Meyer S, Khalid T. Interventions for preventing oral mucositis for patients with cancer receiving treatment. Cohrane Database Syst Rev 2011;13:CD000978.

31. Clarkson JE, Worthington HV, Furness S, McCabe M, Khalid T, Meyer S. Interventions for treating oral mucositis for patients with cancer receiving treatment. Cohrane Database Syst Rev 2010;4:CD001973.

32. Lalla RV, Bowen J, Barasch A, Elting L, Epstein J, Keefe DM, McGuire DB, Migliorati C, Nicolatou-Galitis O, Peterson DE, RaberDurlacher JE, Sonis ST, Elad S; Mucositis Guidelines Leadership Group of the Multinational Association of Supportive Care in Cancer and International Society of Oral Oncology (MASCC/ISOO). MASCC/ISOO clinical practice guidelines for the management of mucositis secondary to cancer therapy. Cancer 2014;120:1453-61.

33. Arbabi-kalati F, Arbabi-kalati F, Deghatipour M, Ansari Moghadam A. Evaluation of the efficacy of zinc sulfate in the prevention of chemotherapy-induced mucositis: a double-blind randomized clinical trial. Arch Iran Med 2012;15:413-7.

34. Hayashi H, Kobayashi R, Suzuki A, Yamada Y, Ishida M, Shakui T, Kitagawa J, Hayashi H, Sugiyama T, Takeuchi H, Tsurumi H, Itoh Y. Preparation and clinical evaluation of a novel lozenge containing polaprezinc, a zinc-L-carnosine, for prevention of oral mucositis in patients with hematological cancer who received high-dose chemotherapy. Med Oncol 2016;33:91.

35. Koch FP, Walter C, Hansen T, Jager E, Wagner W. Osteonecrosis of the jaw related to sunitinib. Oral Maxillofac Surg 2011;15:63-6.

36. Fedele S, Porter SR, D'Aiuto F, Aljohani S, Vescovi P, Manfredi M, Arduino PG, Broccoletti R, Musciotto A, Di Fede O, Lazarovici TS, Campisi G, Yarom N. Nonexposed variant of bisphosphonateassociated osteonecrosis of the jaw: a case series. Am J Med 2010;123:1060-4.

37. Hoefert S, Eufinger H. Sunitinib may raise the risk of bisphosphonaterelated osteonecrosis of the jaw: presentation of three cases. Oral Surg Oral Med Oral Pathol Oral Radiol Endod 2010;110:463-9.

38. Khan AA, Morrison A, Hanley DA, Felsenberg D, McCauley LK, O'Ryan F, Reid IR, Ruggiero SL, Taguchi A, Tetradis S, Watts NB, Brandi ML, Peters E, Guise T, Eastell R, Cheung AM, Morin SN, Masri B, Cooper C, Morgan SL, Obermayer-Pietsch B, Langdahl BL, Al Dabagh R, Davison KS, Kendler DL, Sándor GK, Josse RG, Bhandari M, El Rabbany M, Pierroz DD, Sulimani R, Saunders DP, Brown JP, Compston J; International Task Force on Osteonecrosis 
of the Jaw. Diagnosis and management of osteonecrosis of the jaw: a systematic review and international consensus. J Bone Miner Res 2015;30:3-23.

39. Barasch A, Cunha-Cruz J, Curro FA, Hujoel P, Sung AH, Vena D, Voinea-Griffin AE; CONDOR Collaborative Group, Beadnell S, Craig RG, DeRouen T, Desaranayake A, Gilbert A, Gilbert GH, Goldberg K, Hauley R, Hashimoto M, Holmes J, Latzke B, Leroux B, Lindblad A, Richman J, Safford M, Ship J, Thompson VP, Williams OD, Yin W. Risk factors for osteonecrosis of the jaws: a case-control study from the CONDOR dental PBRN. J Dent Res 2011;90:439-44.

40. van Dalen EC, Mank A, Leclercq E, Mulder RL, Davies M, Kersten MJ, van de Wetering MD. Low bacterial diet versus control diet to prevent infection in cancer patients treated with chemotherapy causing episodes of neutropenia. Cochrane Database Syst Rev 2016;24:4:CD006247.

41. Lerman MA, Laudenbach J, Marty FM, Baden LR, Treister NS. Management of oral infections in cancer patients. Dent Clin North Am 2008;52:129-53.

42. Raber-Durlacher JE, Epstein JB, Raber J, van Dissel JT, van Winkelhoff AJ, Guiot HF, van der Velden U. Periodontal infection in patients treated with high-dose chemotherapy. Support Care Cancer 2002;10:466-73

43. Lark RL, McNeil SA, VanderHyde K, Noorani Z, Uberti J, Chenoweth C. Risk factors for anaerobic bloodstream infections in bone marrow transplant recipients. Clin Infect Dis 2001;33:338-43.

44. Spielberger R, Stiff P, Bensinger W, Gentile T, Weisdorf D, Kewalramani T, Shea T, Yanovich S, Hansen K, Noga S, McCarty J, LeMaistre CF, Sung EC, Blazar BR, Elhardt D, Chen MG, Emmanouilides C. Palifermin for oral mucositis after intensive therapy for hematologic cancers. N Engl J Med 2004;351:2590-8.

45. Hong CH, Napeñas JJ, Hodgson BD, Stokman MA, Mathers-Stauffer V, Elting LS, Spijkervet FK, Brennan MT; Dental Disease Section, Oral Care Study Group, Multi-national Association of Supportive Care in Cancer (MASCC)/International Society of Oral Oncology (ISOO). A systematic review on patients undergoing cancer therapy. Support Care Cancer 2010;18:1007-21.

46. Maheronnaghsh M, Tolouei S, Dehghan P, Chadeganipour M, Yazdi M. Identification of Candida species in patients with oral lesion undergoing chemotherapy along with minimum inhibitory concentration to fluconazole. Adv Biomed Res 2016;5:132.

47. Li XS, Sun JN, Okamoto-Shibayama K, Edgerton M. Candida albicans cell wall ssa proteins bind and facilitate import of salivary histatin 5 required for toxicity. $J$ Biol Chem 2006;281:22453-63.

48. Enoch DA, Ludlam HA, Brown NM. Invasive fungal infections: a review of epidemiology and management options. $J$ Med Microbiol 2006;55:809-18

49. Liu JY, Chen WT, Ko BS, Yao M, Hsueh PR, Hsiao CH, Kuo YM, Chen YC. Combination antifungal therapy for disseminated fusariosis in immunocompromised patients: a case report and literature review. Med Mycol 2011;49:872-8.

50. Oxman MN, Levin MJ, Johnson GR, Schmader KE, Straus SE, Gelb LD, Arbeit RD, Simberkoff MS, Gershon AA, Davis LE, Weinberg A, Boardman KD, Williams HM, Zhang JH, Peduzzi PN, Beisel CE, Morrison VA, Guatelli JC, Brooks PA, Kauffman CA, Pachucki CT, Neuzil KM, Betts RF, Wright PF, Griffin MR, Brunell P, Soto NE, Marques AR, Keay SK, Goodman RP, Cotton DJ, Gnann JW Jr, Loutit J, Holodniy M, Keitel WA, Crawford GE, Yeh SS, Lobo Z, Toney JF, Greenberg RN, Keller PM, Harbecke R, Hayward AR, Irwin MR, Kyriakides TC, Chan CY, Chan IS, Wang WW, Annunziato PW, Silber JL; Shingles Prevention Study Group. A vaccine to prevent herpes zoster and postherpetic neuralgia in older adults. $N$ Engl J Med 2005;352:2271-84.

51. Johnson RW. Herpes zoster in the immunocompetent patient: management of postherpetic neuralgia. Herpes J Ihmf 2003;10:38-45.

52. Dubinsky RM, Kabbani H, El-Chami Z, Boutwell C, Ali H. Practice parameter: treatment of postherpetic neuralgia: an evidence-based report of the Quality Standards Subcommittee of the American Academy of Neurology. Neurology 2004;63:959-65.

53. Schlosser BJ. Lichen planus and lichenoid reactions of the oral mucosa. Dermatol Ther 2010;23:251-67.

54. Ena P, Chiarolini F, Siddi GM, Cossu A. Oral lichenoid eruption secondary to imatinib (Glivec). J Dermatol Treat 2004;15:253-5.

55. Kuten-Shorrer M, Hochberg EP, Woo SB. Lichenoid mucosal reaction to rituximab. Oncologist 2014;19:12-3.

56. Brazzelli V, Muzio F, Manna G, Moggio E, Vassallo C, Orlandi E, Fiandrino G, Lucioni M, Borroni G. Photoinduced dermatitis and oral lichenoid reaction in a chronic myeloid leukemia patient treated with imatinib mesylate. Photodermatol Photoimmunol Photomed 2012;28:2-5

57. Ena P, Chiarolini F, Siddi GM, Cossu A. Oral lichenoid eruption secondary to imatinib (Glivec). J Dermatolog Treat 2004;15:253-5.

58. Wahiduzzaman M, Pubalan M. Oral and cutaneous lichenoid reaction with nail changes secondary to imatinib: report of a case and literature review. Dermatol Online J 2008;14:14 .

59. Carrillo CM, Corrêa FN, Lopes NN, Fava M, Odone Filho V. Dental anomalies in children submitted to antineoplastic therapy. Clinics (Sao Paulo) 2014;69:433-7.

60. Minicucci EM, Lopes LF, Crocci AJ. Dental anomalies in children after chemotherapy treatment for acute lymphoid leukaemia. Leuk Res 2003;27:45-50.

61. Jensen SB, Mouridsen HT, Bergmann OJ, Reibel J, Brünner N, Nauntofte B. Oral mucosal lesions, microbial changes, and taste disturbances induced by adjuvant chemotherapy in breast cancer patients. Oral Surg Oral Med Oral Pathol Oral Radiol Endod 2008;106:217-26.

62. Mazzeo MA, Linares JA, Campos ML, Busamia BE, Dubersarsky C, Lavarda M, Jarchum G, Finkelberg AB. Oral signs of intravenous chemotherapy with 5-Fluorouracil and Leucovorin calcium in colon cancer treatment. Med Oral Patol Oral Cir Bucal 2009;14:E108-13.

63. Rahnama M, Madej-Czerwonka B, Jastrzębska-Jamrogiewicz I, Jamrogiewicz R. Analysis of the influence of parenteral cancer chemotherapy on the health condition of oral mucosa. Contemp Oncol (Pozn) 2015;19:77-82.

64. Imai H, Soeda H, Komine K, Otsuka K, Shibata H. Preliminary estimation of the prevalence of chemotherapy-induced dysgeusia in Japanese patients with cancer. BMC Palliat Care 2013;12:38.

65. Fink M. Vitamin D deficiency is a cofactor of chemotherapy-induced mucocutaneous toxicity and dysgeusia. J Clin Oncol 2011;29:E81-2.

66. Jensen SB, Mouridsen HT, Reibel J, Brünner N, Nauntofte B Adjuvant chemotherapy in breast cancer patients induces temporary salivary gland hypofunction. Oral Oncol 2008;44:162-73.

67. Von Bültzingslöwen I. Effects of 5-Fluorouracil on Oral Barrier Functions [Thesis]. Göteborg (SE): Göteborg University, Institute of Odontology. 2002

68. Fark T, Hummel C, Hähner A, Nin T, Hummel T. Characteristics of taste disorders. Eur Arch Otorhinolaryngol 2013;270:1855-60.

69. Ravasco P. Aspects of taste and compliance in patients with cancer Eur J Oncol Nurs 2005;9 Suppl 2:S84-91.

70. Schindler A, Denaro N, Russi EG, Pizzorni N, Bossi P, Merlotti A, Spadola Bissetti M, Numico G, Gava A, Orlandi E, Caspiani O, Buglione M,Alterio D, Bacigalupo A, De Sanctis V, Pavanato G, Ripamonti C, Merlano MC, Licitra L, Sanguineti G, Langendijk JA, Murphy B. Dysphagia in head and neck cancer patients treated with radiotherapy and systemic therapies: Literature review and consensus. Crit Rev Oncol Hematol 2015;96:372-84.

71. Koizumi T, Fukushima T, Tatai T, Kobayashi T, Sekiguchi N, 
Sakamoto A, Sasaki S. Successful treatment of crizotinib-induced dysgeusia by switching to alectinib in ALK-positive non-small cell lung cancer. Lung Cancer 2015;88:112-3.

72. Mcpherson $\mathrm{T}$, Sherman V, Turner R. Imatinib-associated hyperpigmentation, a side effect that should be recognized. $J$ Eur Acad Dermatol Venereol 2009;23:82-3.

73. Wong M, Sade S, Gilbert M, Klieb HB. Oral melanosis after tyrosine kinase inhibition with Imatinib for chronic myelogenous leukaemia: report of case and review of the literature. Dermatol Online $J$ 2011;17:4

74. Alexandrescu DT, Dasanu CA, Farzanmehr H, Kauffman L. Persistent cutaneous hyperpigmentation after tyrosine kinase inhibition with imatinib for GIST. Dermatol Online J 2008;14:7.

75. Mattsson U, Halbritter S, Mörner Serikoff E, Christerson L, Warfvinge G. Oral pigmentation in the hard palate associated with imatinib mesylate therapy: a report of three cases. Oral Surg Oral Med Oral Pathol Oral Radiol Endod 2011;111:e12-6.

76. Singh N, Bakhshi S. Imatinib-induced dental hyperpigmentaion in childhood chronic myeloid leukemia. J Pediatr Hematol Oncol 2007;29:208-9.

77. Harr T, French LE. Toxic epidermal necrolysis and Steven-Johnson syndrome. Orphanet J Rare Dis 2010;5:39.

78. Allegra A, Alonci A, Penna G, Russo S, Gerace D, Greve B, D’Angelo A, Catena S, Musolino C. Stevens-Johnson syndrome after lenalidomide therapy for multiple myeloma: a case report and a review of treatment options. Hematol Oncol 2012;30:41-5.

79. Urosevic-Maiwald M, Harr T, French LE, Dummer R.StevensJohnson syndrome and toxic epidermal necrolysis in a patient receiving cetuximab and radiotherapy for head and neck cancer. Int $J$ Dermatol 2012;51:864-7.

80. Fang B, Song Y, Ma J, Zhao RC. Severe epidermal necrolysis after bortezomib treatment for multiple myeloma. Acta Haematol 2007;118:65-7.

81. Yeung AK, Goldman RD. Use of steroids for erythema multiforme in children. Can Fam Physician 2005;51:1481-3.

82. Sharma VK, Sethuraman G. Adverse cutaneous reactions to drugs: an overview. J Postgrad Med 1996;42:15-22.

83. Prins C, Gelfand EW, French LE. Intravenous immunoblobulin: properties, mode of action and practical use in dermatology. Acta Derm Venereol 2007;87:206-18.

84. Rai R, Srinivas CR. Suprapharmacologic doses of intravenous dexamethasone followed by cyclosporine in the treatment of toxicepidermal necrolysis. Indian $J$ Dermatol Venereol Leprol
2008;74:263-5.

85. Hunger RE, Hunziker T, Buettiker U, Braathen LR, Yawalkar N. Rapid resolution of toxic epidermal necrolysis with anti-TNF-alpha treatment. J Allergy Clin Immunol 2005;116:923-4.

86. Barclay SC, Turani D. Current practice in dental oncology in the UK Dent Update 2010;37:560-1.

87. Epstein JB, Güneri P, Barasch A. Appropriate and necessary oral care for people with cancer: guidance to obtain the right oral and dental care at the right time. Support Care Cancer 2014;22:1981-8.

88. Caribé-Gomes F, Chimenos-Küstner E, López-López J, FinestresZubeldia F, Guix-Melcior B. Dental management of the complications of radio and chemotherapy in oral cancer. Med Oral 2003;8:178-87.

89. Hong CH, Napeñas JJ, Hodgson BD, Stokman MA, Mathers-Stauffer V, Elting LS, Spijkervet FK, Brennan MT; Dental Disease Section, Oral Care Study Group, Multi-national Association of Supportive Care in Cancer (MASCC)/International Society of Oral Oncology (ISOO). A systematic review of dental disease in patients undergoing cancer therapy. Support Care Cancer 2010;18:1007-21.

90. McCaul LK. Oral and dental management for head and neck cancer patients treated by chemotherapy and radiotherapy. Dent Update 2012;39:135-8, 140

91. Dimopoulos MA, Kastritis E, Bamia C, Melakopoulos I, Gika D, Roussou M, Migkou M, Eleftherakis-Papaiakovou E, Christoulas D, Terpos E, Bamias A. Reduction of osteonecrosis of the jaw (ONJ) after implementation of preventive measures in patients with multiple myeloma treated with zoledronic acid. Ann Oncol 2009;20:117-20.

92. Ripamonti CI, Maniezzo M, Campa T, Fagnoni E, Brunelli C, Saibene G, Bareggi C, Ascani L, Cislaghi E. Decreased occurrence of osteonecrosis of the jaw after implementation of dental preventive measures in solid tumour patients with bone metastases treated with bisphosphonates. The experience of the National Cancer Institute of Milan. Ann Oncol 2009;20:137-45.

93. Epstein JB, Silverman S Jr, Paggiarino DA, Crockett S, Schubert MM, Senzer NN, Lockhart PB, Gallagher MJ, Peterson DE, Leveque FG. Benzydamine $\mathrm{HCl}$ for prophylaxis of radiation-induced oral mucositis: results from a multicenter, randomized, double-blind, placebo-controlled clinical trial. Cancer 2001;92:875-85.

94. Campisi G, Di Fede O, Musciotto A, Lo Casto A, Lo Muzio L, Fulfaro F, Badalamenti G, Russo A, Gebbia N. Bisphosphonate-related osteonecrosis of the jaw (BRONJ): run dental management designs and issues in diagnosis. Ann Oncol 2007;18 Suppl 6:vi168-72. 